\title{
EDITORIAL
}

\section{Are the people marginalized through knowledge economy?}

'Knowledge economy (KE)' or 'knowledge-based economy' is understood as the recognition of the role of knowledge and technology in economic growth. It is well appreciated that 'knowledge' represented by 'human capital' and technology has always been fundamental to economic development. KE contributes to production and services based on knowledge-intensive activities through an accelerated pace of technical and scientific advancement. It relies more on intellectual capabilities than on physical inputs or natural resources. The rapid marginalization of traditional norms and indigenous knowledge is inevitable when development activities are solely based on new knowledge. The traditional and indigenous knowledge about utilization of natural resources are by and large environmentally friendly and ecologically sustainable. In KE, greater importance is placed on innovation for economic growth, competitiveness, increased significance of education, and lifelong learning. Through innovation, we could become globally competitive and improve productivity and human welfare. However, Sri Lanka being a country with a significant number of people relying on rural livelihoods such as agriculture and fisheries, it is imperative that modernization of traditional livelihoods should be performed with caution. When new technologies and innovations are applied to improve our traditional livelihoods that have evolved over generations maintaining environmental integrity, it is necessary to seriously keep in mind that all citizens must be ensured of sharing the economy. This should be done in such a manner that available choices are examined before applying new knowledge, science and innovation to make sure that they do not increase inequality in the process. There have been many technological advances in agriculture such as improved seed cultivars, pesticides, mechanization, and application of remote sensing in farming methods. In coastal fisheries, there are many community-based fisheries management strategies, which have evolved over hundreds of years through indigenous knowledge of resource users that have ensured sustainability and sharing of resources with equity.

Innovation however can also have a downside. As a result of innovations, loss of many farm labour jobs has taken place; the expertise of farmers and farm workers is gradually being replaced by the advances through innovation. It is apparent that farm jobs are being lost because agricultural farmers are no longer needed as many unskilled workers. In paddy cultivation, farm workers' skills are no longer needed or valued, because machines, improved seed varieties and chemicals are considered more important in the wake of new knowledge. Coastal fisheries sector is no exception. Community-based fisheries management systems tend to disappear due to the implementation of advanced fishing technology and increased fishing capacity coupled with information and communication technology.

The ultimate goal of a knowledge-based economy is the eradication of poverty and inequality. Innovation is expected to reduce the cost of production of goods, and develop new goods and services. KE is often focused on the linkage between technology and labour productivity, which is defined as the amount of output per unit of labour input. As there is a danger of increasing inequality through innovations, it is imperative that an innovation strategy be envisaged, which empowers grassroot level communities in such a way that all citizens can share the benefits of KE. Policymakers therefore have to be concerned about where and how innovation should be applied. 